\title{
Communications
}

\section{Necrogranulomatous scleritis treated by an onlay scleral graft}

\author{
D. SEVEL AND A. ABRAMSON \\ From the Department of Ophthalmology, University of Cape Town, and the Groote Schuur Hospital, \\ Cape Town, South Africa
}

Necrogranulomatous scleritis (scleromalacia perforans) may be associated with rheumatoid arthritis (rheumatoid nodule of the sclera), with the necrotizing vasculitis group of diseases, or confined to the eye without overt evidence of associated systemic disease (Sevel, I965, $1966,1967, \mathrm{r} 968 \mathrm{a}, \mathrm{b})$. The purpose of this paper is to review the clinical features of a further case of necrogranulomatous scleritis in the light of its present treatment. The value of a scleral onlay graft is described with special emphasis on its histology.

\section{Case report}

A white male retired book-keeper aged $7 \mathbf{r}$ years was first seen in the Eye Out-Patients Department of Groote Schuur Hospital on August 15, 1967 , when he complained of epiphora.

\section{Examination}

The visual acuity was $6 / 12$ and $6 / 7 \cdot 5$ in the right and left eyes respectively. Both pupils were small and perilimbal injection was noted in association with circumferential corneal fluorescein staining. The intraocular tension was $30 \mathrm{~mm}$. $\mathrm{Hg}$ in the right eye and $25 \mathrm{~mm}$. $\mathrm{Hg}$ in the left. On this occasion both naso-lacrimal ducts were syringed and were found to be patent.

\section{Treatment}

Chloramphenicol ointment was applied locally three times a day, and a week later the symptoms were less marked; there was no corneal staining but the eyes were still injected. Neosporin drops were prescribed three times a day.

\section{Course}

On October 3, 1967, the eyes had become troublesome and much more injected and the patient complained of blurred vision, ocular itching, and epiphora. There were marginal subepithelial infiltrates with maximal conjunctival hyperaemia and oedema was evident over the upper halves of both eyes. As this area was tender a diagnosis of bilateral episcleritis was made and betamethasone drops three times a day were given in addition to the chloramphenicol ointment. Oxyphenbutasone tablets, one three times a day, were added to the regime but on November 14, 1967, patches of episcleritis were still evident near the superior limbus in both eyes. The visual acuity had improved to $6 / 5$ in each eye, and with a near correction to $\mathrm{N}_{5}$.

On January 9, 1968, redness and oedema were noted in larger areas of the conjunctiva adjacent to the limbus. The patient now had a fluctuating course of improvement and exacerbation and on 
April 2 posterior lenticular opacities were noted in both eyes. At this stage, a diagnosis was made of necrogranulomatous scleritis involving the area of sclera adjacent to the limbus above the horizontal meridian of both eyes.

During the next 6 months the patient became more photophobic and pain became a marked and discomforting feature. The visual acuity with correction on February 4 , 1969, was counting fingers at 2 metres in the right eye and 6/24 in the left. The intraocular tension was within normal limits.

On March 4, 1969, thinning of the upper nasal sclera on the right side became evident. This area was blue and bulged. Conjunctival hyperaemia and chemosis were evident in the surrounding area. In September, 1969, anterior uveitis was noted and the patient also developed what appeared to be a steroid allergy. In view of the intense local inflammation and pain, intensive systemic steroid therapy was commenced.

At this admission to hospital the patient gave a history of having been admitted to a surgical ward and subsequently to a medical ward in 1967 for dysphagia which was then attributed to cerebrovascular disease. A barium swallow at that time showed a much dilated hypopharynx but no neuromuscular discoordination. There was narrowing of the oesophagus in the postcricoid region and a diagnosis of crico-pharyngeal achalasia was considered.

During the present admission, the visual acuity was $6 / 60$ and $6 / 5$ in the right and left eyes respectively. There was anterior uveitis in both eyes with a fairly marked flare and cells. The venereal disease reference laboratory test was negative. Results of a full blood count, including a differential count, and erythrocyte sedimentation rate were entirely normal. LE cells were not found. A barium meal on this occasion showed a duodenal bulb deformity suggestive of an active peptic ulcer. An $x$-ray of the chest confirmed pectus excavatum and generalized osteoporosis of the dorsal vertebral bodies. Gastroscopy was normal.

The patient was then discharged with no anterior chamber activity and was seen subsequently in the out-patient department. He continued to have much ocular discomfort. His eyes were irritable and it was decided that an onlay scleral graft should be performed on the right side because of imminent rupture of the eye at the site of the supra-nasal staphyloma.

\section{Operation}

The patient was re-admitted to hospital on February 3, 1970, and was given Io per cent. intravenous mannitol $(\mathrm{r} \cdot 5 \mathrm{~g} . / \mathrm{kg}$. body weight) 3 hours before the operation. Under general anaesthesia the conjunctiva was incised in the upper nasal quadrant and a limbal-based flap was fashioned. A staphyloma was identified extending from the medial end of the superior rectus insertion to the upper border of the medial rectus muscle. The donor sclera was obtained from a patient who had died on the same day. The cornea of the donor was excised at the limbus and a "doughnut-shaped" piece of sclera was cut $3 \mathrm{~cm}$. from the limbus. The episclera and underlying uveal tissue were carefully dissected and a length of sclera measuring approximately $2.5 \mathrm{~cm}$. was cut so as to cover the staphylomatous area and the immediate uninvolved sclera. The scleral graft was fashioned to extend from the medial end of the superior rectus insertion to the lower border of the medial rectus muscle. The sclera was notched so as to embrace the medial rectus muscle as the staphyloma extended to this muscle. The graft passed underneath the superior rectus muscle where the maximum amount of staphyloma was noted. The graft was sutured in situ with 5/o chromic catgut and the conjunctiva was sutured with $6 / 0$ chromic catgut.

\section{Postoperative course}

In the immediate postoperative period there was dramatic relief of the distressing pain. Chloramphenicol and betamethasone drops were given three times a day and he was discharged on betamethasone drops.

On April 14, 1970, he was re-admitted, having developed a hyphaema in the operated eye after a minor injury to the eye. At that time he also noted a melaena. Both eyes were padded and strict rest in bed was ordered, and the hyphaema cleared. 
$X$-ray studies revealed peptic ulceration on the lesser curvature of the stomach, and the duodenal bulb was again noted to be deformed. He was referred to the gastroenterology out-patients clinic, where a diagnosis of a bleeding duodenal ulcer was made.

He was treated for the duodenal ulcer with the appropriate drugs, but his general condition deteriorated while he was being followed-up in the gastroenterology out-patients clinic, and he was therefore re-admitted on August 4, 1970, to a medical ward.

At this stage he was in a confused state, emaciated, and obviously ill. A brain scan was normal. Gastroscopy was normal. $X$-ray examination of the skull and mastoids showed no abnormality.

\section{Termination}

The patient died on September 3, 1970, and an autopsy was performed on the following day.

\section{Autopsy examination}

The body was that of a thin emaciated elderly white male. The tongue, thyroid gland, trachea, and main bronchi showed no abnormality. The oesophagus showed some leucoplakia of the distal third and in the postcricoid region the lumen of the oesophagus was narrowed for a distance of approximately $2 \mathrm{~cm}$. At this site the lumen admitted only the tip of the little finger. The lungs were oedematous and showed areas of lower lobe bronchial pneumonia. The heart and heart valves were normal. The spleen was atrophic. The liver showed no unusual features. The brain was essentially normal. The stomach showed flattening of the mucosa and a mild degree of atrophic gastritis. In the first part of the duodenum there were two small scarred patches, each approximately $1.5 \mathrm{~cm}$. in diameter, due to previous healed peptic ulcers. The small and large bowel showed no abnormality. The kidneys showed a decrease in the width of the cortex but were otherwise normal.

The only positive findings at autopsy were the stenosis at the pharyngo-oesophageal junction and bilateral bronchopneumonia.

Histology of the lungs showed bronchopneumonia and sections taken from the area of the stricture at the pharyngo-oesophageal junction revealed fibrosis of the lamina propria which was also the seat of an active inflammatory process. Many of the small arteries and arterioles were surrounded by a mantle of polymorphonuclear leucocytes. Scanty plasma cells were also seen in this area. Scattered atrophic muscle fibres were seen in the underlying skeletal muscle but no inflammatory signs were noted in the muscle coat.

No pathology was noted in the kidneys.

\section{Comments}

The patient died from emaciation and bronchopneumonia. The pharyngo-oesophageal stricture determined the emaciation. The mild inflammatory reaction noted at the stricture was probably due to the irritation caused by a naso-gastric tube which had been used to feed the patient.

\section{Histological examination of the eyes}

RIGHT EYE

The main pathology was a necrogranulomatous reaction involving the region of the sclera anterior to the equator and extending as far as the limbus (Fig. I). There was evidence of peripheral keratitis and superficial corneal vascularization. The central cornea was uninvolved. The scleral reaction was characterized by areas of "sequestroid" (Fig. 2) and "smudgy" necrosis which were surrounded by granulomatous reaction-the predominant cells being lymphocytes, plasma cells, occasional giant cells, and a few eosinophils (Fig. 3). The granulomatous reaction involved the sclera and caused separation of the scleral fibres. This granulomatous reaction was also noted in the surrounding episcleral tissue and particularly in the choroid, which had as a result become thickened. 


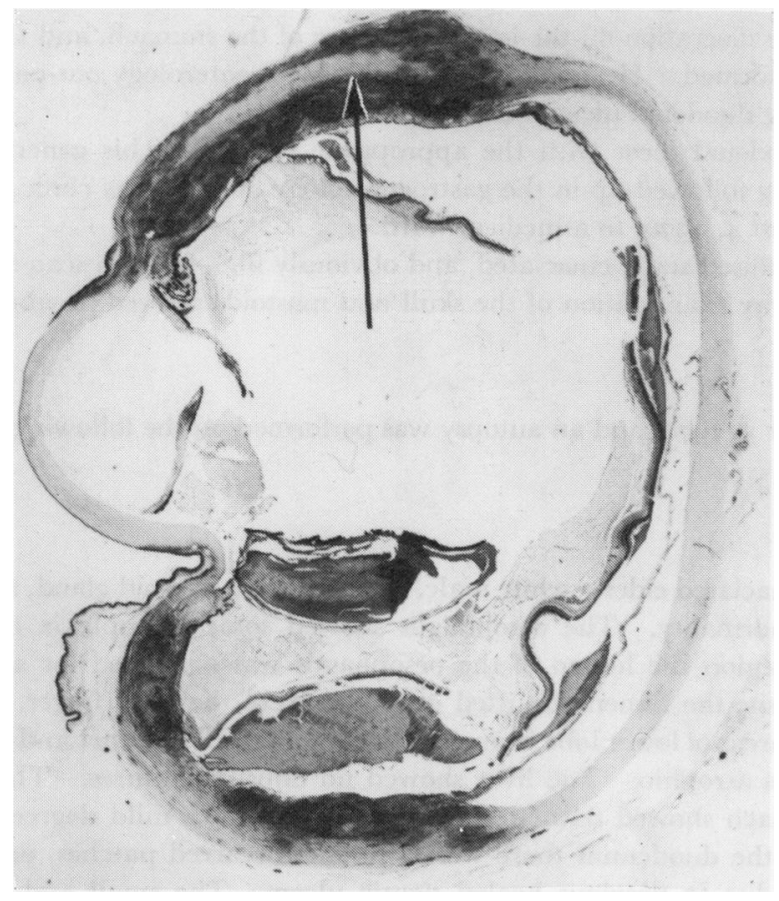

FIG. I Reaction of necrogranulomatous scleritis involving sclera anterior to the equator and extending as far as the limbus. Scleral graft (arrowed) is surrounded by a granulomatous reaction. Haematoxylin and eosin. $\times 3.5$

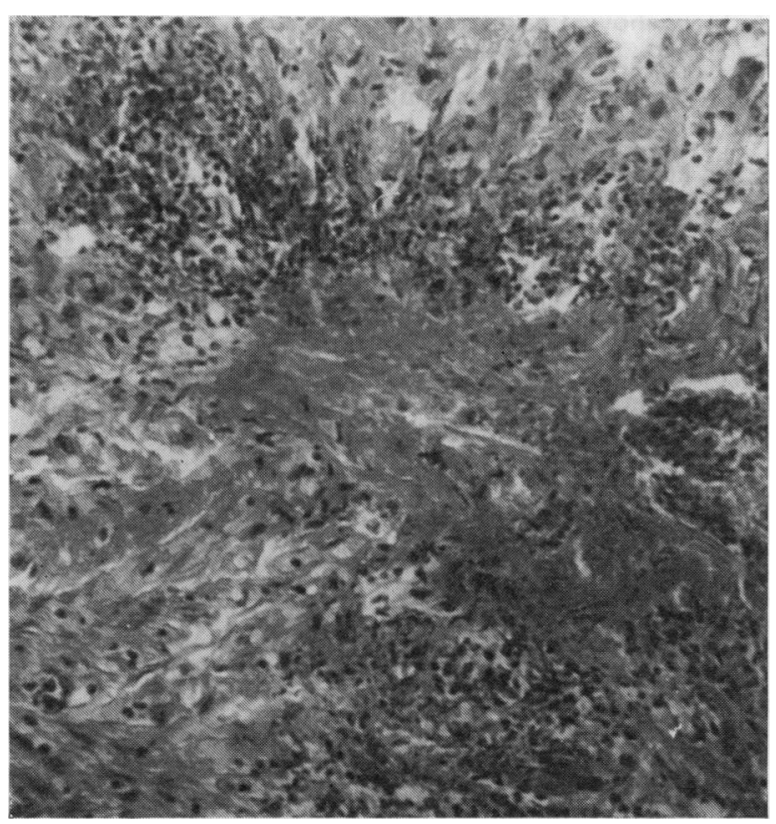

FIG. 2 Area of "sequestroid" necrosis surrounded by granulomatous reaction. Haematoxylin and eosin. $\quad \times 120$

The overlying retina was detached but not involved by the inflammatory reaction. Eosinophilic exudate and a few chronic inflammatory cells were present in the subretinal space. The rest of the retina was in situ and the ganglion cells were sparse.

The anterior sclera overlying the ciliary body was absent and was replaced by the granulomatous tissue. The scleral graft covered this area and was surrounded and invaded by a granulomatous reaction (Figs 4 and 5, overleaf). A chronic cyclitis was noted and the filtration angle was occluded 


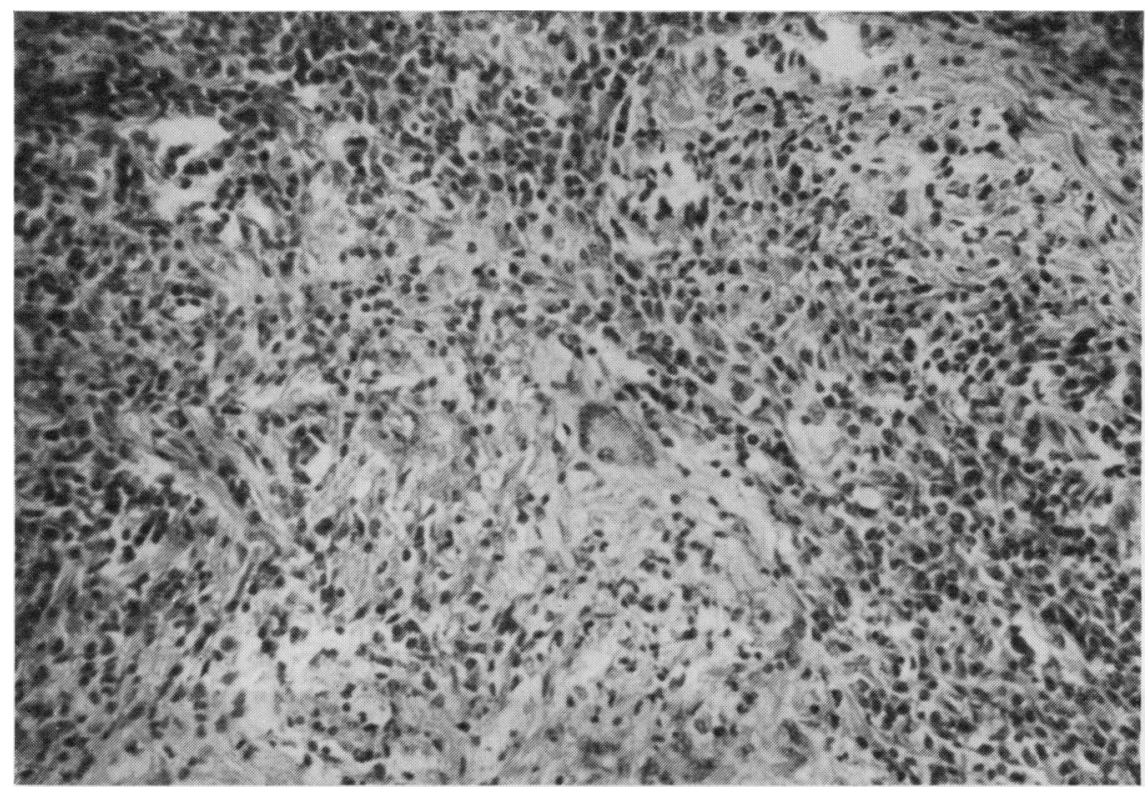

FIG. 3 Giant cells, lymphocytes, and plasma cells in surrounding granulomatous reaction. Haematoxylin and eosin. $\times 120$

by peripheral anterior synechiae. There was a mild chronic iritis, rubeosis iridis, and ectropion uveae. The lens was cataractous. The optic discs showed posterior bowing of the lamina cribrosa but there was no obvious atrophy of the optic nerve fibres.

LEFT EYE

The essential pathology was again that of a necrogranulomatous scleritis similar to that observed in the right eye. The reaction extended from the equator to the optic nerve (Fig. 6 ) on the one side while on the opposite side the reaction extended from the equator to the supraciliary region. There was a marked granulomatous cyclitis on the one side. The filtration angle was occluded by peripheral anterior synechiae, and there was chronic iritis with rubeosis iridis and ectropion uveae. There were posterior synechiae to the cataractous lens. The granulomatous reaction extended into the episclera and to a lesser extent into the underlying choroid. The retina was detached but not invaded by the reaction and there was subretinal eosinophilic exudate in which a few inflammatory cells were noted.

The lamina cribrosa was bowed posteriorly but there was no atrophy or gliosis of the optic nerve.

\section{Discussion}

The features of this case are typical of necrogranulomatous scleritis confined to the eye without overt (clinical or post mortem) evidence of systemic necrotizing vasculitis or rheumatoid arthritis (Sevel I966, I967, I968a,b).

The poor response to medical treatment is similar to that of previous cases described.

To date there is no specific therapy for necrogranulomatous scleritis.

Cortisone has been used both topically and systemically in the treatment of necrogranulomatous scleritis with varying results (Talkov, Colpoys, Davis, Papper, and Fienberg, I95I ; Mundy, Howard, Stillman, and Bevans, I95I ; Ashton and Hobbs, I952 ; Anderson and Margolis, 1952; Cury, Breakey, and Payne, 1956; Marquard, 1956; Petrohelos and Wolter, I956; Boberg-Ans, I958; Bick, I959; Frayer, I960; Harper, I 960; 


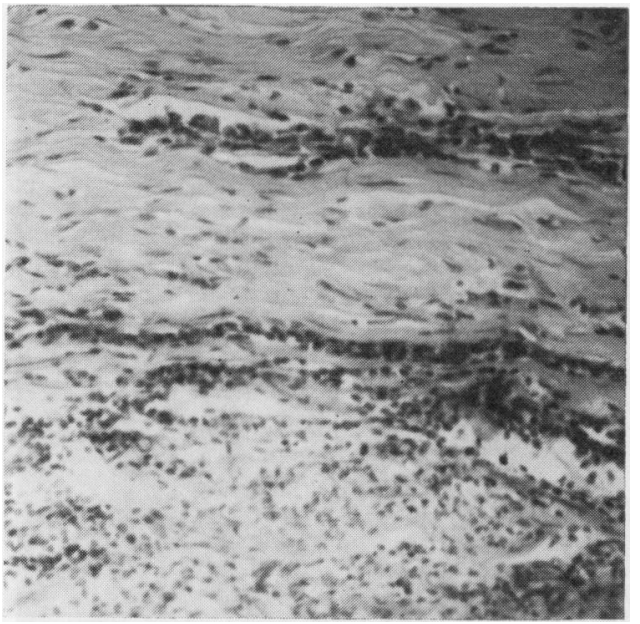

FIG. 4 Granulomatous reaction surrounding scleral graft. Haematoxylin and eosin. $\times 160$

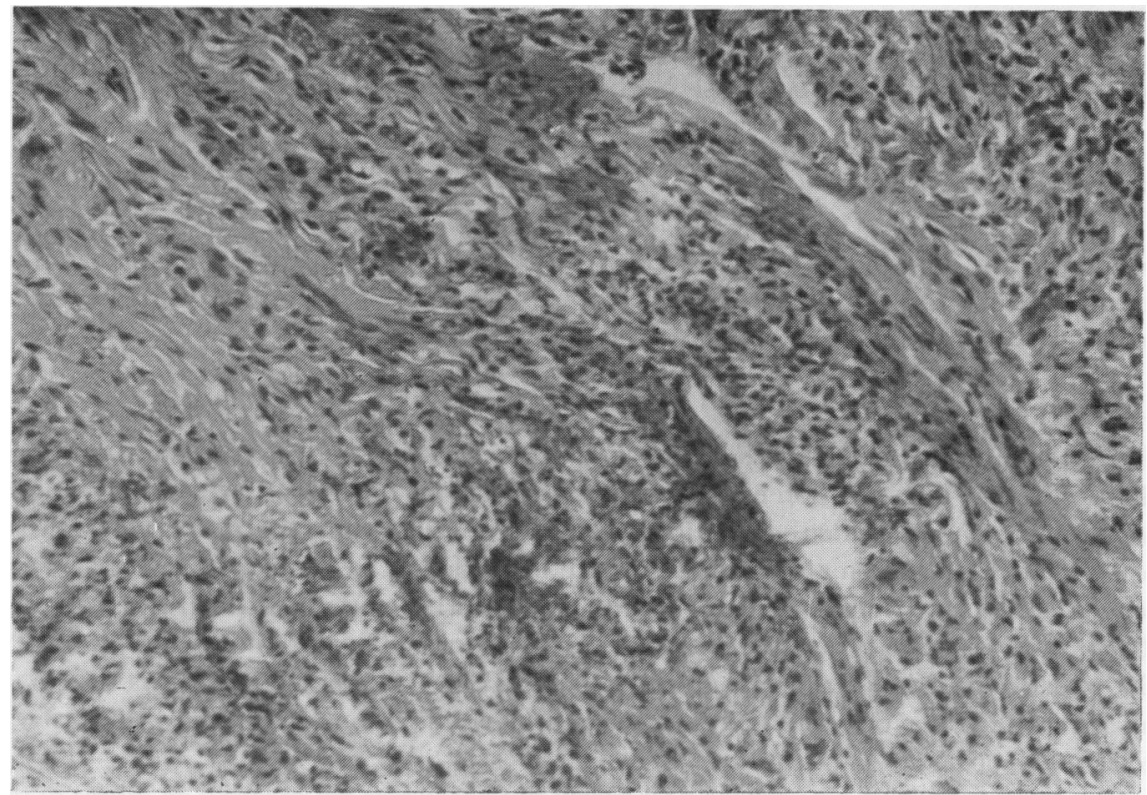

FIG. 5 Inflammatory reaction invading scleral graft. Haematoxylin and eosin. $\times 120$

McCarthy, I96r ; Taffet and Carter, I96I ; Rosenthal and Williams, I962; Wolter and Boldt, I963; Boylan, I964; Merz, 1964). In the cases described the initial response was usually satisfactory but this success was short-lived and after a varying period of time (6 months to 4 years) the affected eye had to be enucleated. The development of necrogranulomatous scleritis is characterized by exacerbations and remissions, and it is therefore difficult to be certain whether or not the initial beneficial effects are due to the cortisone. It is equally difficult to assess the long-term effects of cortisone as there may be cases which have been treated successfully and have not required enucleation. In those few cases which have been reported, the diagnosis of necrogranulomatous scleritis is doubtful.

The relationship of the episclera and the choroid to the scleral reaction appears to be of particular importance. Superficial scleral nodules (episcleritis) respond well to cortisone 


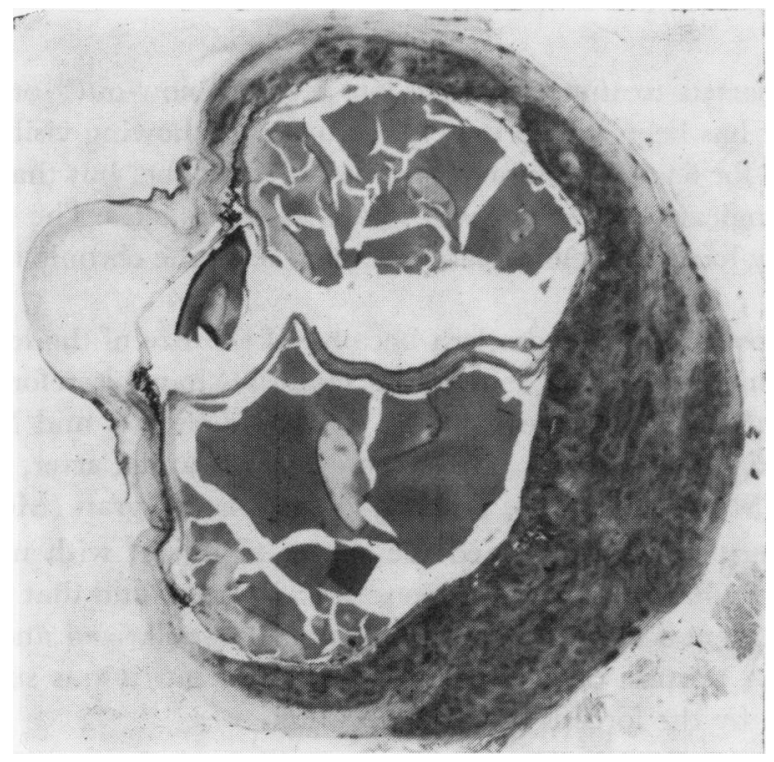

FIG. 6 Section of left eye, showing necrogranulomatous scleritis extending from equator to optic nerve posteriorly. Haematoxylin and eosin. $\times 3.5$

therapy, whereas deep-seated foci of necrogranulomatous scleritis respond poorly (Sevel, I968a,b). While it has been shown that albumin may pass in bulk through the sclera (Bill, 1965), it is likely that larger and more complicated molecules such as cortisone and antibodies cannot reach the deep scleral lesions.

The value of subconjunctival injection of cortisone is doubtful with necrogranulomatous scleritis. In fact, Tooker (I93I) and Swan and Butler (I950) related the focus of necrogranulomatous scleritis to the "trauma" of subconjunctival injection. In one case in a series it was the opinion of the ophthalmic surgeon that the site of necrogranulomatous scleritis corresponded to the location of the subconjunctival injection of cortisone. Jones (1965) suggested that necrogranulomatous scleritis in some cases might occur at the sites of subconjunctival injections of cortisone.

While there may be an initial response to the systemic cortisone therapy, its long-term use has not been very successful in this condition. There is a possibility that cortisone may in fact intensify foci of vasculitis as has been shown in the vasculitis of rheumatoid arthritis (Levin, Rivo, Scott, Figueroa, Fred, and Barrett, I953; Toone and Irby, I955; Kemper, Baggenstoss, and Slocumb, 1957; Bywaters, I957; Sokoloff and Bunim, I957; Smyth and Gum, ig6r).

The cortisone may, in some unknown manner, activate or accelerate a pre-existing vascular abnormality sufficiently to produce clinical manifestations. It has been suggested that the development of the vasculitis may be related to fluctuation or high dosage of the cortisone (Johnson, Smyth, Holt, Lubchenco, and Valentine, I959).

Watson, Lobascher, Sabiston, Lewis-Faning, Fowler, and Jones (1966) compared oxyphenbutazone (Tanderil) and prednisone in the treatment of episcleritis and scleritis and concluded that oxyphenbutazone was effective in the treatment of episcleritis. Too few cases of scleritis were studied to allow final conclusions to be drawn.

In the Eye Department of Groote Schuur Hospital it has been found that episcleritis responds well to oxyphenbutazone whereas necrogranulomatous scleritis responds poorly. This response is probably due to the excellent blood supply of the episclera as compared to that of avascular sclera. 
SURGICAL TREATMENT

Surgery should not be resorted to unless there is an actual "blow-out" or ectasia and bulging of the sclera, for it has been shown that numerous eyes showing visible blue uvea only have been enucleated for fear of imminent rupture of the globe, but that when these eyes were examined histologically the sclera was found to be intact. The transparency of the sclera is explained by localized scleral dehydration due to the chronic inflammatory reaction (Sevel, ig66).

It is not possible to remove the diseased sclera because of the size of the lesion and the complications of perforation, and various reinforcing materials have therefore been used, e.g. mucous membrane graft (Van de Hoeve, I934; Renard, Lelièvre, and Mazel, I953; Duke-Elder and Leigh, I965), scleral graft (Gross, I953; Taffet and Carter, I 96 I), fascia lata graft (Armstrong and McGovern, I955; Bick, 1959), and aortic graft (Merz, I964).

Armstrong and McGovern (1956) examined the eye of a patient with necrogranulomatous scleritis in which a fascia lata graft had been used. They found that the graft was firmly adherent to the adjacent sclera and episclera; it was vascularized and showed no evidence of breakdown. A portion of sclera showed necrosis, but it was suggested that this was the site of fixation by the forceps used at operation.

Blum and Salamoun ( 1963 ) used a "dough-nut shaped" fascia lata graft in order to cover a larger defect. Necrogranulomatous scleritis occurs more commonly in the anterior sclera but may recur in neighbouring locations and the "doughnut-shaped" graft offers additional protection against this possibility.

Merz (1964) used aortic tissue as a reinforcing graft. The advantages of this material are its availability, elasticity, strength, and malleability. This last feature is of particulag importance from the technical point of view.

Sclera, as shown in this case, was found to be excellent tissue to form a reinforcinge patchwork for scleral ectasia. The cornea is removed, the required breadth of sclera is marked, and the graft is cut and then sutured over the section of defective sclera. Sclera is ideal material as it can easily be cut for a "doughnut-shaped" graft if there is a possibility of the necrogranu'omatous reaction spreading circumferentially. The scleral graft is then sutured into position, special notches being pre-cut at the site of the rectus muscles. As shown in this case, an onlay scleral graft becomes incorporated into the pre-existing sclera. A granulomatous reaction surrounds the graft and invades the edges. The pain of necrogranulomatous scleritis is explained by the stretching caused by the inflammatory reaction of the tightly packed scleral fibres of the scleral collagen. This pain is particularly marked once a "blow-out" occurs. The scleral onlay graft prevents further stretching and the pain becomes less marked, a feature well demonstrated in this patient who experienced immediate postoperative relief of pain.

\section{Summary}

A case is described of necrogranulomatous scleritis confined to the eye without overt evidence of associated systemic disease.

The present concepts of treatment, both medical and surgical, are considered and the value of an onlay scleral graft is discussed.

This investigation was supported by the Gratitude Fund for Ophthalmology, the Ophthalmological Research Fund, and the Willem Goosen Trust Fund. 


\section{References}

anderson, B., and margolis, c. (1952) Amer. 7. Ophthal., 35, 9 I 7

ARmStrong, K., and McGovern, v. J. (1955) Trans. ophthal. Soc. Aust., 15, i 10

Ashton, N., and hoBBs, H. E. (1952) Brit. 7. Ophthal., 36, 373

віск, м. w. (1959) A.M.A. Arch. Ophthal., 61, 907

BILL, A. (1965) Arch. Ophthal. (Chicago), 74, 248

BLUM, F. G., and SALAmoun, s. G. (1963) Ibid., 69, 287

BOBERG-ANS, J. (1958) Acta ophthal. (Kbh.), 36, 33

BOylan, c. E. (1964) Surv. Ophthal., 9, 252

BYWATERs, E. G. L. (1957) Ann. rheum. Dis., 16, 84

Gury, D., BReAkey, A. s., and PAyne, B. F. (1956) A.M.A. Arch. Ophthal., 55, $26 \mathrm{I}$

DUKE-ELDER, S., and LEIGH, A. G. (1965) "System of Ophthalmology", vol. 8, pt 2, p. I049.

Kimpton, London

FRAYER, w. c. (1960) Arch. Ophthal. (Chicago), 64, 58

GROss, R. (1953) "La scléromalacie perforante et les maladies qui s'en rapprochent". Thèse.

Maurice Fabre, Lyon

haRper, J. y. (ig6o) A.M.A. Arch. Ophthal., 63, 663

Johnson, R. L., SMYTh, c. J., hOlt, G. W., LUbGhenco, A., and valentine, E. (1959) Arthr. and

Rheum., 2, 224

JONES, B. J. (1965) Personal communication

Kemper, J. W., Baggenstoss, A. H., and SLOcumb, c. H. (1957) Ann. intern. Med., 46, 83 I

LEVIN, M. I., RIVo, J. B., SCOTt, w., FIGUeroa, W. G., FRED, L., and BARRETT, T. F. (1953) Amer. $\mathcal{J}$.

Med., 14, 265

McCARThy, J. L. (1961) Amer. F. Ophthal., 51, 6o

MARQUARD, H. A. (1956) Acta ophthal. (Kbh.), 34, 245

MERZ, E. H., (1964) Amer. F. Ophthal., 57, 766

MUNDy, W. L., hOWARD, R. M., Stillman, P. H., and BeVANs, м. (195I) Arch. Ophthal. (Chicago),

45, 53 I

PETrohelos, M. A., and WOlter, J. R. (1956) Ibid., 55, 22 I

RENARD, G., LELIÈvRE, and MAZEL (1953) Bull. Soc. franç. Ophtal., 66, 243

rosenthal, J. W., and williams, G. T. (r962) Amer. F. Ophthal., 54, 862

SEVEL, D. (1965) Trans. ophthal. Soc. U.K., 85, 357

- (1966) Thesis. University of London

(1967) Amer. F. Ophthal., 64, I 125

(1968a) Brit. 7. Ophthal., 52, 453

(1968b) S. Afr. med. F., 42, 155

SмYTh, c. J., and Gum, о. в. (196r) Arthr. and Rheum., 4, I

sokoloff, L., and Bunim, J. J. (1957) $\quad$ f. chron. Dis., 5, 668

swan, K. c., and BUtLER, J. B. v. (1950) (Quoted by Swan, K. C. (195I) A.M.A. Arch. Ophthal.,

$45,630)$

TAFFET, S., and CARTER, G. z. (1961) Amer. F. Ophthal., 52, 693

TAlkov, R. H., Colpoys, F. L., DAVIS, R. K., PAPPER, s., and FIENBerg, R. (I95I) Arch. intern. Med.,

87, 879

TOOKER, c. w. (1931) Amer. F. Ophthal., r4, 91 I

TOONE, E. C., and IRBY, R. (1955) Amer. F. Med., 18, 4 I

VAN DER HOEVE, J. (1934) Arch. Ophthal., II, I I I

WATSON, P. G., LOBASGheR, D. J., SABISTON, D. W., LeWis-FANing, E., FOWLeR, P. D., and JONES, B. R.

(1966) Brit. F. Ophthal., 50, 463

WOlter, J. R., and вOLDT, H. A. (1963) Amer. F. Ophthal., 55, 922 